\title{
Prostituição: Que Modelo Jurídico-Político para Portugal?*
}

\author{
Marta Graça \\ Manuela Gonçalves ${ }^{1}$ \\ ${ }^{1}$ Universidade de Aveiro, Aveiro, Portugal. E-mail de contato: msgraca@yahoo.com
}

\section{INTRODUÇÃO}

\begin{abstract}
o longo da história, a prostituição foi encarada de diversas forA mas, dependendo dos contextos social, político e moral em que se encontra inserida. A leitura dessa prática como algo aceito, tolerável, suscetível de vigilância/controle ou como alvo de punição jurídica e/ou social depende da influência de discursos patriarcais, judaicocristãos, moralistas, higienistas, de despenalização, entre outros, conforme seja útil ou não para o regime político vigente.
\end{abstract}

Na maioria das vezes associada ao comportamento desviante e ao crime, a prostituição conheceu, em seus primórdios, a aceitação social, não estando vulnerável a processos de exclusão, discriminação ou estigmatização. De acordo com Roberts (1996), foi com o declínio do matriarcado e a divisão entre as mulheres conforme seu comportamento sexual que a visão sobre a prostituição assumiu outras conotações.

\footnotetext{
* Este estudo foi financiado pela Fundação para a Ciência e a Tecnologia (FCT/MEC), por meio de fundos nacionais (Programa de Investimentos e Despesas de Desenvolvimento da Administração Central - PIDDAC) e cofinanciado pelo Fundo Europeu de Desenvolvimento Regional (Feder) através do Programa Operacional Factores de Competitividade (Compete) no âmbito do projeto PEst-C/CED/UI0194/2013; e pela bolsa de doutoramento da FCT - SFRH/BD/78139/2011. Gostaríamos ainda de agradecer aos pareceristas anônimos de DADOS - Revista de Ciências Sociais a leitura cuidadosa e os valiosos contributos, que se constituíram momentos de reflexão e aprendizagem.
}

DADOS - Revista de Ciências Sociais, Rio de Janeiro, vol. 59, n-2, 2016, pp. 449 a 480. 
Essa divisão constituiu um ponto fulcral na medida em que terá servido de base para o exercício do poder e para o controle social por parte do Estado em diversos momentos.

Em Portugal, assim como um pouco por toda a Europa, a prostituição foi alvo de diferentes modelos jurídico-políticos. De uma fase caracterizada pela existência de diversas disposições legais com tendências regulamentaristas (...-1853) à concretização do regulamentarismo (1853-1962), em que as prostitutas eram toleradas e estavam sujeitas ao cumprimento de prescrições, passando pelo proibicionismo (1963-1982), com o estabelecimento de leis para a criminalização, e atualmente adotando o abolicionismo (1983-presente), em que a prostituta não é criminalizada, mas sim quem pratica o lenocínio, a prostituição e o trabalho sexual, no sentido mais amplo, continuam no cerne do debate, dividindo opiniões entre os defensores do trabalho sexual como categoria profissional e os que o consideram uma violação dos direitos humanos.

Neste artigo, as teorias feministas são tomadas como quadro de referência e de influência na evolução histórico-legal dos modelos jurídicopolíticos de intervenção na prostituição, sobretudo a partir da segunda metade do século XIX. Todavia, escolhemos como ponto de partida o século XII a fim de contextualizarmos e compreendermos os discursos hegemônicos produzidos nos diversos contextos históricos, sociais e políticos, os quais, tendo se constituído em Saber-Poder (Foucault, 1990), informaram e formaram as hegemonias sociais, legitimando-se em regulamentos ou proibições. Num segundo momento, focalizamos o debate atual empreendido em Portugal apresentando e interpretando, à luz dos paradigmas da opressão, do empoderamento e do polimorfo, enunciados por Weitzer (2009), a opinião dos técnicos que fazem parte das instituições que dirigem serviços a trabalhadores(as) do sexo sobre a moldura jurídico-política. Muito embora tomemos como análise o caso português, o debate é extensível a outros países, como nos demostram Weitzer (2009) e Doezema (1998), entre outros autores.

A finalidade deste artigo consiste, por um lado, em analisar as diferentes perspectivas sobre o trabalho sexual e enriquecer o debate com os relatos de experiência dos profissionais de proximidade, e, por outro, indagar sobre sua influência na qualidade de micropoderes na relação com as práticas sociais e o poder constituído do Estado (Foucault, 
2008). Cabe ressaltar que procuramos conhecer a opinião dos técnicos levando em conta a atuação ideológica da instituição, e não seus percursos individuais.

Para isso, entendemos trabalho sexual como uma "atividade comercial de prestação de serviços, em que é desempenhado um comportamento com um significado sexual ou erótico para quem compra", efetuada entre adultos e com mútuo consentimento (Oliveira, 2011:15). Estão contidas no trabalho sexual as situações que envolvem a troca comercial de serviços sexuais, performances ou produtos, incluindo atividades de contato físico direto entre compradores e vendedores (prostituição, lap dance) e as de estimulação sexual indireta (pornografia, striptease, sexo por telefone, sessão de sexo ao vivo, webcams eróticas). A indústria do sexo refere-se a trabalhadores, gerentes, donos, agências, clubes, associações e ao mercado envolvido no comércio sexual - legal ou não (Weitzer, 2010).

\section{LEGITIMAÇÃO DO DEBATE FEMINISTA NOS MODELOS JURÍDICO-POLÍTICOS DE INTERVENÇÃO NO TRABALHO SEXUAL}

O interesse pela temática da sexualidade acompanha a evolução da ciência e as práticas sociais. Mesmo quando se supôs reprimida, numerosos discursos de diversas áreas multiplicaram-se para satisfazer uma vontade de saber e, assim, contrariar essa asserção, conforme esclarece Foucault (1990) ao formular a "hipótese repressiva" e ao introduzir o conceito de "dispositivo de sexualidade". Decorrente dessa vontade de saber, tal proliferação dos discursos, que se evidenciou sobretudo nos séculos XVIII e XIX, possibilitou a ampliação do conhecimento que, numa relação dialógica com o poder, permitiria consolidar a hegemonia social e a produção legislativa para o estabelecimento de interditos e proibições (Foucault, 1990). O Saber-Poder, na qualidade de estratégia de controle dos indivíduos e da população, permite, em seu contexto, a definição das normas e a classificação dos desvios, atribuindo um lugar à prostituta nos discursos oficiais, de natureza médica, legal e política.

Entre os diversos discursos patentes que influenciaram a adoção de diferentes modelos jurídico-políticos, destacamos a pluralidade das narrativas feministas, que começaram a ganhar expressão a partir da segunda metade do século XIX, por abarcarem uma ampla compreensão dos discursos de opressão e de empoderamento presentes na literatura 
científica e no debate social sobre prostituição, conforme definidos por Weitzer (2009). Embora a literatura feminista seja bastante rica, multiplicando-se em diversas perspectivas sobre a prostituição, como demonstra Bromberg (1998), sobressai a dicotomia antagônica, ora como crime, ora como trabalho. Na base dessas concepções, encontra-se, de forma mais ampla, o entendimento de ambas as partes quanto à sexualidade e ao corpo. Na primeira situação, o corpo da mulher é percebido como objeto sexual que satisfaz as necessidades sexuais dos homens dentro de uma heterossexualidade legítima da opressão patriarcal; na segunda, é sujeito sexual, considerando a procura e a obtenção do prazer, a liberdade e o poder (Sanders, O'Neill e Pitcher, 2011; Weitzer, 2009, 2010; Piscitelli, 2005).

Assim, dessa primeira perspectiva, denominada feminismo radical, a prostituição é considerada crime (Barry, 1986), visando à exploração do ser humano, sendo não só uma forma de violência dirigida à mulher que se prostitui mas a todas as mulheres (Farley, 2004), uma vez que se trata de uma instituição patriarcal que reforça a dominação masculina e a desigualdade de poder entre os gêneros (Giddens, 1993). Nessa concepção, a prostituição é moralmente errada, está relacionada com o comportamento degenerativo, e as prostitutas são vítimas que exercem a atividade sob a coação de terceiros, servindo, por essa via, de base para molduras jurídico-políticas que refletem a preocupação governamental de reduzir ou erradicar a indústria do sexo (Mossman, 2007), como é o caso do proibicionismo ou do abolicionismo, muito embora assentes em pressupostos morais diferentes.

No modelo proibicionista, todas as formas de prostituição são inaceitáveis e, consequentemente, ilegais. Nesse sentido, o(a) prostituto(a) e as atividades associadas à prostituição são criminalizadas por meio da aplicação de pena de prisão ou do pagamento de multa, como sucede na maioria dos Estados Unidos da América. Já no abolicionismo, encontramos os países que adotaram o modelo nórdico (por exemplo, a Suécia), em que a tônica está na criminalização dos clientes, apelidados de prostituidores, e nas atividades associadas, não criminalizando o(a) prostituto(a). Existem ainda países como Portugal e Brasil em que a prostituição não é proibida, os clientes e os(as) trabalhadores(as) do sexo não são alvo de punição, mas são criminalizadas atividades relacionadas, como a gestão de bordéis ou a prática de lenocínio. No caso do Brasil, a prostituição encontra-se integrada como atividade profissional na Classificação Brasileira de Ocupações $(\mathrm{CBO})^{1}$. 
Convém acautelar que as narrativas construídas em relações de poder no que tange ao abolicionismo são diferentes e situadas em momentos distintos. Na segunda metade do século XIX, por exemplo, centram-se na preocupação com o tráfico de brancas (Doezema, 1998); na década de 1970, os argumentos se atêm à violência contra as mulheres; atualmente, assumem posição radical ao percepcionar a prostituição como violência sexista, que encontra lógica e sustentação no patriarcado, na estratificação social e na vulnerabilidade das mulheres (Piscitelli, 2012). Por outro lado, as narrativas sobre o tráfico humano multiplicaram-se nos últimos anos, estabelecendo uma interseção entre migração e prostituição; e, mais uma vez, a divergência e a controvérsia estão presentes (Kempadoo, 2012).

Em outra linha, mais próxima do reconhecimento da prostituição como trabalho, evidenciam-se os defensores do regulamentarismo, que postulam que a prostituição, embora não desejável, assume uma função social e, portanto, deve ser alvo de regulamentação e de controle do Estado a fim de proteger a ordem e a saúde pública. Normalmente os(as) trabalhadores(as) do sexo se encontram sujeitos a registro, licenciamento e, em alguns casos, são obrigados a controle médico-sanitário. Alguns países adotaram essa abordagem visando diminuir crimes associados, como crime organizado, corrupção policial, prostituição infantil e tráfico de seres humanos para fins de comércio sexual (Mossman, 2007). São casos paradigmáticos desse sistema a Alemanha e a Holanda.

No contexto ativista dos anos 1960 e 1970, emerge outra corrente de inspiração liberal, empenhada na defesa da opção livre pela prostituição. Surge também a designação trabalho sexual, utilizada pela primeira vez por Carol Leigh, ativista e trabalhadora do sexo (Delacoste e Alexander, 1998).

No campo teórico, a problematização do gênero como construção social legitimada pela sociedade patriarcal e a rejeição do determinismo biológico (Bourdieu, 1999; Scott, 1995) permitiram, de um lado, a ruptura epistemológica e, de outro, o questionamento dos mecanismos que operam para o exercício do poder simbólico da dominação masculina, tal como Bourdieu (1999) nos elucida. Em resposta ao patriarcado, a prostituição pode assumir-se como ato de rebeldia, uma vez que afronta as convenções masculinas, representa a liberdade sobre o corpo e o poder da mulher quando é ela quem estabelece as próprias re- 
gras de conduta, de negociação comercial, de ocupação do espaço público, além de obter independência financeira.

A essa lógica se contrapõe outra perspectiva, em que a prostituição é considerada um trabalho. Para os defensores dessa posição, o feminismo radical não contempla a opção livre de ingresso na atividade nem a capacidade das mulheres para se organizarem em torno do trabalho sexual (Chapkis, 1997), de que são exemplos os movimentos promovidos pelos(as) trabalhadores(as) do sexo para a defesa de seus direitos e dos quais resultaram diversas associações no âmbito mundial (Lopes, 2006; Delacoste e Alexander, 1998; Roberts, 1996). Apenas Nova Gales do Sul (Austrália) e Nova Zelândia adotaram um quadro que permite a defesa dos direitos e deveres dos(as) trabalhadores(as) do sexo em sua íntegra.

Segundo Weitzer (2009), os discursos apresentados estão relacionados com os paradigmas da opressão e do empoderamento presentes quer na literatura científica, quer nos discursos sociais. No primeiro caso, os estudos encontram-se enviesados, focados apenas nas experiências negativas; no segundo, nos aspectos positivos, negligenciando outras situações diferenciadas. Ambos são considerados unidirecionais e demasiado simplistas, uma vez que ignoram a complexidade das circunstâncias econômicas, as desigualdades entre homens e mulheres, assim como a diversidade de trabalhadores na indústria do sexo (Sanders, O'Neill e Pitcher, 2011; Weitzer, 2009). Para Weitzer, o trabalho sexual não pode ser reduzido a um dos paradigmas, sugerindo, assim, o paradigma polimorfo para designar uma constelação de arranjos ocupacionais, relações de poder e experiências de trabalho diferentes.

\section{EVOLUÇÃO HISTÓRICO-LEGAL DA PROSTITUIÇÃO EM PORTUGAL}

\section{Disposições Legais Pré-regulamentaristas (...-1853)}

As primeiras disposições legislativas com restrições concernentes às prostitutas terão surgido no século XII (Carmo e Fráguas, 2003; Barra da Costa e Alves, 2001; Pais, 1984; Gomes, 1913), muito embora, e de acordo com Mattoso (1993), durante o século XIII, a prostituição fosse aceita com naturalidade pela sociedade de então, e entre os nobres e os clérigos existiam as concubinas e as barregãs. Nesse período, apesar de decretadas diversas medidas para a regulamentação, a prostituição foi 
sendo mais ou menos aceita, e a repressão nunca foi efetuada com perseverança.

Foucault (1990) explica que, até o século XVII, a sexualidade e os assuntos relativos a ela fluíam com naturalidade, tendo sua suposta repressão iniciado nessa época. Todavia, o autor considera essa repressão ilusória, na medida em que a proliferação de discursos sobre a sexualidade, a que se assistiu de forma mais intensa nos séculos posteriores, permitiu a ampliação do Saber, peça essencial de uma estratégia de controle do indivíduo e da população.

No século XVIII, com o dispositivo de sexualidade, surgiram também os interditos e as proibições, a divisão entre o lícito e o ilícito (Foucault, 1990). Por essa via, o poder, entendido como a "multiplicidade de correlações de força imanentes ao domínio onde se exercem e constitutivas de sua organização [...], toma corpo nos aparelhos estatais, na formulação da lei, nas hegemonias sociais" (Foucault, 1990:88-89). O poder é, então, exercido em contexto através das suas formas terminais (a soberania do Estado, a lei, a unidade global de uma dominação), assumindo um papel no controle e na regulação da sexualidade, em que se inclui a prostituição.

É com a criação da Intendência Geral de Polícia da Corte e Reino, em 1760 , que as restrições à prostituição vão se tornar mais consistentes. Segundo Subtil (1993), são preocupações desse organismo, entre outras, prevenir a criminalidade e desenvolver estudos sobre o estado sanitário da população com vistas à promoção da segurança e do bemestar. A fim de preservar a moral e os bons costumes no espaço público, é emitido o Aviso de 27 de abril de 1780, ordenando que as prostitutas sejam conduzidas à casa de correção de Santa Maria de Crotona e delimitando os espaços onde podem permanecer (Gomes, 1913). Um ano mais tarde, prescreve que as prostitutas sejam sujeitas a um registro e a uma inspeção médica periódica; que sejam presas e tratadas quando se encontrarem doentes; e que sejam expulsas se fizerem escândalo ou resistirem à polícia ( $\mathrm{D}^{\prime}$ Azevedo, 1864). No entanto, a primeira manifestação legal do regulamentarismo surge em 1836, com o Código Administrativo, que estabelece tolerância para com prostitutas e casas públicas (Pais, 1984).

Em 1837, é constituído o Conselho de Saúde Pública, e, quatro anos mais tarde, surge o primeiro estudo sobre a matéria, de onde emergem as linhas orientadoras de futuros regulamentos (Santos, 1982). Esse es- 
tudo, o primeiro no âmbito científico realizado em Portugal pelo médico Santos Cruz, apresenta como principal objetivo o combate à propagação do "vírus venéreo" (Santos Cruz, 1984:46), referindo-se à sífilis, com a apresentação de um projeto de regulamento policial e sanitário para "obviar os males causados à moral e à saúde pela prostituição pública" (ibidem:329).

A prostituição torna-se, assim, pela primeira vez, objeto de um discurso produzido pelos centros de poder, encontrando na argumentação científica, que até então inexistia, justificativa e fundamento para a necessidade e a utilidade pública da tolerância (Liberato, 2002). A questão sexual é então reenquadrada, passando a ser assunto do Estado, de interesse público (idem), em que as diversas estratégias de controle vão se consolidar de forma que permitam a eficácia do Saber-Poder (Foucault, 1990).

Além da preocupação com a saúde, sobressaía a questão da preservação moral e dos bons costumes. A partir de meados do século XIX, a mulher burguesa ganha lugar nos espaços públicos, sendo facilmente confundida com as meretrizes, pelo que os chefes de família se movimentam para delimitar fronteiras e espaços (Pais, 2008). Já os esforços legislativos incidiam sobretudo na rua, local de coexistência de dois universos: boêmia e transgressão e "normalidade institucional aceita" (Guinote e Oliveira, 1989:341), a fim de delimitá-los. Assim, a prática permanecia escondida mas controlada, não se contestando sua utilidade para a sociedade e para a organização conjugal/familiar da época.

Nessa sequência, Santos (1982) defende que o fenômeno deve ser entendido tendo como base a família monogâmica patriarcal. Como esta persegue objetivos econômicos, é por isso incapaz de dar respostas às aspirações sexuais de seus membros. Essa questão se encontra relacionada com a ideia prevalecente de então de família "instituição", a qual, mais tarde, por meio de transformações associadas à mudança nos modos de produção, ao êxodo rural e à urbanização, será substituída pela família "companheirismo", em que o casamento se torna uma opção livre dos cônjuges e sua finalidade consiste na promoção do bem-estar do casal e dos filhos (Burgess e Locke, 1960).

Tal como a família, a prostituição se assume como uma instituição (Pais, 2008), complementar do lar (Santos, 1982), com funções simbólicas específicas, reguladoras dos instintos, com a finalidade de garantir 
a dominação patriarcal, a harmonia sexual e familiar dos portugueses (Silva, 2007) e sobre a qual se deve exercer controle. Para Pais (2008), os únicos lugares da sexualidade são a alcova ou o bordel; à família, no plano da sexualidade, apenas é atribuída a função reprodutiva. Refletindo todas essas contradições, Vieira (1892 apud Oliveira, 2004:205) sintetiza afirmando que a prostituição é "proibida pela religião, reprovada pela moral, mas autorizada pela lei e necessitada pela sociedade".

No que concerne à prostituição masculina, salientamos que é raramente referida. De acordo com Guinote e Oliveira, desenrolava-se, mas era intolerada, ignorada e tomada como inexistente pela moralidade dominante; "[...] constituía uma perversão e uma imoralidade bem mais grave que a prostituição feminina" (1989:373).

\section{Regulamentarismo (1853-1962)}

Com a introdução do Código Administrativo de 1836, a constituição do Conselho de Saúde Pública, o estudo efetuado por Santos Cruz, os discursos moralistas e as transformações da época, encontravam-se dados os primeiros passos para a adoção do sistema regulamentarista, que se concretiza em 1853 e entra oficialmente em vigor em 1858. Santos (1982) refere que todos os regulamentos obedecem a uma estrutura, assuntos e medidas semelhantes. Para o autor,

[...] os regulamentos, por detrás da máscara humanitária e liberalizadora, constituíram um contrato unilateral que rodeava as operárias do sexo de uma apertada malha, destinada a servir exclusivamente a sua clientela (Santos, 1982:10).

Os regulamentos constituíam, por sua vez, importantes fontes de receita. Nesse período, é ainda elaborado um estudo no Porto por D'Azevedo (1864), que servirá de base para o regulamento de meretrizes nessa cidade; e, em 1865, surge um novo regulamento em Lisboa, que apresenta mudanças no nível das multas e do controle sanitário. Na mesma data, outro regulamento, denominado Braamcamp, consagra a obrigatoriedade da matrícula nos registros policiais ou na administração local, a inspeção higiênico-sanitária periódica e o porte do livreto que deveria ser apresentado sempre que solicitado pelas autoridades, condições necessárias para que a prostituta fosse considerada tolerada (Barra da Costa, 2003). 
Mais tarde, em 1913, surgem os primeiros movimentos abolicionistas organizados em Portugal, com a criação da Liga de Moralidade Pública, que visava à erradicação da prostituição, coexistindo, dessa forma, duas posições: os defensores do regulamentarismo e os defensores do abolicionismo. Os primeiros argumentavam a pertinência da regulamentação de modo que impedisse o escândalo público e a limitação das casas de toleradas para o controle das doenças. No entanto, essas medidas, de acordo com os abolicionistas, fracassaram, uma vez que permitiram o aumento da clandestinidade e a inspeção periódica se revelou ineficaz no combate à propagação das doenças, pois não contemplava as clandestinas e os clientes; paralelamente, esse sistema favoreceu outras atividades que se estabeleceram em torno da prostituição.

O abolicionismo é ainda inspirado pelo movimento que teve início na Europa em 1875 e materializa-se com as convenções internacionais em 1910 e em 1933 sobre o tráfico de brancas, difundindo-se universalmente por meio da convenção internacional em 1949, realizada pela Assembleia Geral da Organização das Nações Unidas (ONU), conforme informação presente no Decreto-Lei 44.579, publicado no Diário do Governo, I Série, em 19 de setembro de 1962. Em Portugal, ganha expressão em 1924, com o I Congresso Feminista, a que se segue, em 1926, o I Congresso Nacional Abolicionista, organizado pela então fundada Liga Portuguesa Abolicionista (Barra da Costa, 2003; Carmo e Fráguas, 2003; Pacheco, 2000). Não obstante essa influência, e após um período de alheamento e de algum facilitismo da prostituição, associado às transformações políticas da implementação da República, a partir de 1925 o Estado volta a um efetivo controle sobre a vida nas ruas (Guinote e Oliveira, 1989) e continua o regulamentarismo.

Na década de 1940, o Estado torna-se mais interventivo e repressivo contra os "estados de perigosidade social" (Bastos, 1997:223), intensificando a repressão policial e o combate à solidariedade popular, que alertava as prostitutas sobre as rusgas policiais. Com o Decreto-Lei 35.042 , de 20 de outubro de 1945, o Estado equipara a prostituta ao mendigo, ao proxeneta, ao homossexual e aos praticantes de roubos ou aos associados com malfeitores, sobretudo as mulheres que exerciam o ofício na clandestinidade e sobre as quais se tomavam medidas consideradas regenerativas e preventivas (Bastos, 1997).

O período da ditadura corresponde, assim, à intensificação das medidas de repressão da prostituição. As doenças sexualmente transmissí- 
veis, como a sífilis, contribuem para a construção desse estatuto de perigosidade social, considerando as prostitutas impuras e uma ameaça de contágio aos portugueses entendidos como "honestos e inocentes" (Silva, 2007). Surgem ainda movimentos associados à caridade e à reconversão das mulheres com o objetivo de erradicar a atividade por meio de assistência social e reeducação das prostitutas (idem).

Para Barra da Costa e Alves (2001), o regulamentarismo, em sua missão de impedir o escândalo público, delimitar espaços e pessoas, e controlar doenças sexualmente transmissíveis, reforça a ideia do homem "inocente", que deve ser protegido do contágio venéreo e imoral, e acentua a dicotomia entre mulheres "bem-comportadas e malcomportadas", sendo as últimas consideradas seres anormais, de hereditariedade mórbida, degenerados, doentes mentais (Bastos, 1997), em que o comportamento sexual é considerado desviante e objeto de procedimentos normalizadores por parte do Estado. Para Pais (2008:60), “o regulamentarismo, que em Portugal dominou quase toda a segunda metade do século XIX, não foi mais que uma peça do projeto global de exclusão, marginalização e enclausuramento de que foram alvo as prostitutas".

Com a Lei 2.036, de 9 de agosto de 1949, inicia-se a fase pré-abolicionista. Essa lei promulga as bases da luta contra as doenças contagiosas, definindo que compete à Direção-Geral da Saúde promover o exame sanitário das pessoas que se entregarem à prostituição; proíbe novas matrículas e casas de toleradas; e ordena o encerramento de casas que não cumpram as prescrições higiênicas e, por esse motivo, constituem foco de infecção e perigo para a saúde pública. Nessa data, a maior parte dos países se enquadrava em sistemas abolicionistas ou proibicionistas (Santos, 1982).

\section{Proibicionismo (1963-1982)}

O sistema proibicionista concretiza-se com o Decreto-Lei 44.579, de 19 de setembro de 1962, que estabelece a proibição do exercício da prostituição a partir de 1o de janeiro de 1963. Esse decreto, que surge na sequência do movimento feminista radical referido e das direções tomadas por diversos países, prescreve o encerramento das casas; despejo e apreensão de todos os bens; destruição dos livros de registro das matrículas e livretos; punição com pena de prisão até um ano e multa para indivíduos que conscientemente fomentem, favoreçam ou de algum 
modo facilitem o exercício da prostituição ou nela intervenham com fins lucrativos; equipara as prostitutas a vadios para efeito de aplicação de medidas de segurança; e às menores de 16 anos define a aplicação de medidas de proteção, assistência ou educação, conforme previstas no Decreto-Lei 44.288, de 20 de abril de 1962. Nesse diploma, omitem-se a reinserção das prostitutas (Barra da Costa e Alves, 2001) e a clientela (Pacheco, 2000), sendo que, de acordo com Santos (1982:17), “[...] o 8o Juízo Correcional de Lisboa apressou-se a esclarecer que o decreto do governo não visava punir a conduta daqueles que mantêm relações sexuais com prostitutas". Assume-se também que esses dispositivos legais abrangem apenas a prostituição no feminino.

De acordo com Carmo e Fráguas (2003), essas medidas não erradicaram a prostituição, servindo para piorar a condição sobretudo das prostitutas de rua, expondo-as a perigos diversos, como agressões, assaltos e fugas da polícia. No entanto, a prostituição que envolvia altos membros do governo não sofria as mesmas represálias, como o caso Ballet Rose ${ }^{2}$, que resultou em prisão e depois em liberdade condicional para uma "costureira de meninas", e os clientes não foram penalizados (Pacheco, 2000; Santos, 1982).

Em 1977, no primeiro governo constitucional, é composta uma comissão para elaborar sugestões legislativas e estudar o fenômeno. De acordo com Santos (1982), tratava-se de um estudo enviesado e pouco científico que tendia para o abolicionismo. Serviu para elaborar um anteprojeto, em 1978, que previa manter o proibicionismo e ampliava o conceito de crime de prostituição aos proxenetas e rufiões (Santos, 1982).

Apesar das modificações na mentalidade, nas quais se enquadra a abertura ao diálogo sobre a sexualidade que acompanhou a ruptura política do 25 de Abril (Ferreira e Barreira, 1993), as tentativas de desvincular a lei das questões morais não foram bem-sucedidas (Silva, 2007). Mesmo depois do fim do período ditatorial, as prostitutas continuaram cumprindo pena de prisão e só depois de 1983 puderam ver a atividade descriminalizada.

\section{Abolicionismo (1983-presente)}

Em 1ํ de janeiro de 1983, com o Decreto-Lei 400/82, de 23 de setembro, a prostituição é descriminalizada. Hoje prevalece a punição do lenocínio, isto é, quem, profissionalmente ou com intenção lucrativa, fomentar, favorecer ou facilitar o exercício da prostituição por outra pessoa 
ou a prática de atos sexuais de relevo é punido com pena de prisão de seis meses a cinco anos (Código Penal Português, art. 169, no 1). É também punido aquele que se dedicar ao tráfico de pessoas para a prática, em outro país, da prostituição (Código Penal Português, art. 169).

Segundo Carmo e Fráguas (2003), o lenocínio é um crime difícil de comprovar, visto que, muitas vezes, as mulheres mantêm três tipos de relação com os proxenetas: medo, acordo mútuo ou relação afetiva; por isso, as situações não são denunciadas nem são aplicadas medidas punitivas.

Cabe ainda referir que, entre 1983 e 2001, existiram diversas tentativas, por parte dos governos civis, para voltar ao proibicionismo. Muito embora a prostituição em si não seja ilegal, algumas atividades que constituem ofensa contra a decência e a ordem pública serviam de argumento para as autoridades deterem para identificação e/ou averiguação ou conduzir a julgamento especialmente aquelas que operavam nas ruas (Silva, 2007). Em 2001, o Tribunal Constitucional declarou essas detenções anticonstitucionais (Carmo e Fráguas, 2003).

Carmo e Fráguas (2003) e Oliveira (2004) consideram que o modelo vigente corresponde a um vazio legal que ignora a existência da atividade e não reconhece direitos nem poder reivindicativo aos(às) trabalhadores(as) do sexo. Atualmente, debate-se uma mudança legislativa em que subsistem, tal como no passado, os defensores do abolicionismo e os que consideram a prostituição um trabalho, argumentando que se trata de uma escolha, não difere de outras profissões e pode ser uma ocupação bem-sucedida (Pacheco, 2000).

Na lógica desse debate, em 2011, é criada a Rede sobre Trabalho Sexual (RTS) em Portugal, constituída pela maioria das instituições que desenvolvem trabalho junto aos(às) trabalhadores(as), investigadores e profissionais do sexo. A RTS faz clara distinção entre o que é trabalho sexual, adotando a designação já citada sugerida por Oliveira (2011) e por Weitzer (2010), e o que são exploração, tráfico e abuso, condenando veementemente essas três últimas práticas. Sua missão está relacionada à promoção e à defesa dos direitos humanos, sociais e laborais dos(as) trabalhadores(as) do sexo e ao combate à discriminação, ao estigma e à violência dirigida a esses(as) trabalhadores(as). No âmbito desse trabalho, foi lançada, em junho de 2012, uma campanha de sensibilização com o mote "Trabalho sexual é trabalho"3.

Em dezembro de 2012, a Agência Piaget para o Desenvolvimento $(\mathrm{APDES})^{4}$ e a RTS, em parceria com juristas, entregaram aos grupos 
parlamentares da Assembleia da República Portuguesa uma proposta de alteração jurídica do trabalho sexual, com enfoque em direitos humanos, saúde ocupacional e condições de trabalho. O sentido dessa proposta aponta para o enquadramento do trabalho sexual numa categoria profissional. Algumas recomendações que dela constam são: não criminalização; alteração do art. 169 do Código Penal, criminalizando a exploração sexual, mas permitindo a organização do trabalho sexual; regulamentação da atividade, e não das pessoas, isto é, sem delimitação de zonas para o exercício, sem rastreios, registros e matrículas obrigatórios; criação de "uma comissão de acompanhamento da reforma legislativa constituída por representantes da classe profissional em questão e membros da sociedade civil em contato com essa população" (Agência Piaget para o Desenvolvimento, Rede sobre Trabalho Sexual e Peixoto, 2012:7); promoção de ações de sensibilização de combate ao estigma e à discriminação e ações de educação para a saúde e a cidadania dirigida a trabalhadores(as) do sexo; e, por fim, promoção do acesso à educação e à formação profissional.

As propostas apresentadas têm como base a experiência de trabalho de proximidade junto a essa população, a análise de modelos adotados em outros países e um questionário de recolha de opinião, aplicado no âmbito da RTS, que abrangeu 126 pessoas que exercem trabalho sexual. Esse estudo preliminar concluiu que a maioria defende os direitos e deveres da prostituição como trabalho. Das pessoas abordadas, 120 defendem o reconhecimento legal da atividade, e 83 afirmam que assumiriam a atividade; os que não assumem não o fazem pelo preconceito e pelo receio da reação da família.

\section{METODOLOGIA}

O estudo empreendido, situado num plano de investigação de natureza qualitativa, tem a finalidade de analisar as perspectivas dos profissionais das instituições, que dirigem respostas a essa população, sobre a atual moldura jurídico-política e o trabalho sexual, procurando indagar sua influência como micropoderes na relação com as práticas sociais e o poder constituído do Estado.

\section{Participantes e Seleção}

Para este estudo, consideramos todas as instituições no território português que desenvolvem trabalho junto aos(às) trabalhadores(as) do sexo. Com base no mapeamento de serviços dirigidos a esses(as) traba- 
lhadores(as) em Portugal continental, elaborado pelo Grupo Português de Ativistas sobre Tratamentos VIH/SIDA Pedro Santos (GAT), em 2012, contactamos 18 instituições ${ }^{5}$. Foram ainda contactadas cinco instituições que não constavam do mapeamento, tendo sido sugeridas por outras ${ }^{6}$. Essas instituições são, em sua maioria, organizações não governamentais, sendo que duas se encontram integradas formalmente na Direção-Geral da Saúde (serviço público).

Foram efetuadas 23 entrevistas semiestruturadas a coordenadores de equipe ou a elementos da equipe técnica, num total de 32 indivíduos. Essas entrevistas foram realizadas entre outubro de 2012 e março de 2013, de forma presencial, exceto quatro, que foram respondidas por escrito, e outras quatro via Skype. Os entrevistados consentiram a participação no estudo e a gravação de áudio nas entrevistas, tendo as respectivas transcrições sido enviadas para que eles fizessem eventuais retificações. No Quadro 1, apresentamos a caracterização geral dos sujeitos entrevistados.

Quadro 1

Caracterização dos Entrevistados

\begin{tabular}{|l|l|c|}
\hline \multicolumn{2}{|c|}{ Caracterização dos Entrevistados } & Total \\
\hline \multirow{3}{*}{ Gênero } & Feminino & 27 \\
& Masculino & 5 \\
\hline \multirow{3}{*}{ Formação acadêmica } & Psicologia & 15 \\
& Serviço social & 8 \\
& Educação social & 3 \\
& Sociologia & 1 \\
& Medicina & 1 \\
& Enfermagem & 1 \\
\multirow{3}{*}{ Posição na instituição } & Engenharias & 3 \\
\hline
\end{tabular}

Fonte: Elaboração das autoras.

Essas instituições desenvolvem respostas e apoios dirigidos a trabalhadores(as) do sexo, sendo que a mais antiga iniciou em 1967, e a mais recente em 2012. Nos anos 1980 e 1990, quatro instituições iniciaram trabalho nessa área, mas é nos anos 2000 que se registra um número maior de novas iniciativas, num total de 18 , o que provavelmente se re- 
laciona com a abertura de candidaturas a projetos financiados pelo programa ADIS/SIDA, da Direção-Geral da Saúde.

\section{Técnica de Coleta e Procedimentos de Tratamento de Dados}

Recorremos à entrevista semiestruturada na medida em que, de acordo com os objetivos, "importa obter dados comparáveis de diferentes participantes" (Coutinho, 2011:291). Para analisar o corpus, optamos pela técnica de análise de conteúdo das respostas, do tipo categorial ou temática (Ghiglione e Matalon, 2005; Bardin, 2004), tendo sido considerada a técnica mais adequada por suas dimensões descritiva e interpretativa.

Esta pesquisa se encontra inserida num estudo estrutural cujo objetivo é analisar ocorrências, identificar características e atributos por meio da análise taxonômica, sem operacionalização de variáveis, e comparar fontes diferentes (Amado, Costa e Crusoé, 2013). Para isso, adotamos os princípios e procedimentos indicados na literatura especializada sobre essa técnica (Amado, Costa e Crusoé, 2013; Strauss e Corbin, 2008; Ghiglione e Matalon, 2005; Bardin, 2004; Vala, 1986). Recorremos ainda ao software de análise qualitativa webQDA, pelas potencialidades oferecidas por esse programa para o trabalho em ambiente colaborativo online (Neri de Souza, Costa e Moreira, 2011) e pela dimensão do corpus em análise.

\section{APRESENTAÇÃO E DISCUSSÃO DE RESULTADOS}

As opiniões dos técnicos relativamente à moldura política que deve vigorar podem ser agrupadas em quatro tipos de posição, levando em conta os paradigmas definidos por Weitzer (2009):

1) Opressão: defesa da manutenção do abolicionismo, a qual foi manifestada por 3 instituições. Uma delas acrescentou que essa questão é indiferente para a continuidade de seu trabalho e irrelevante para os(as) trabalhadores(as) do sexo, e outra mencionou ainda encontrar-se aberta ao debate sobre o assunto, apesar de defender o abolicionismo.

2) Empoderamento: necessidade de mudança legal, no sentido do reconhecimento legal da atividade (11 instituições).

3) Polimorfo: sem opinião formada quanto ao sentido da mudança legislativa, mas com abertura para sua discussão (7 instituições), 
demonstrando preocupação sobretudo com o respeito e com os direitos dos(as) trabalhadores(as) do sexo. Assim, qualquer que seja o rumo a ser tomado, consideram que o mais importante são as pessoas. Nessa posição, incluímos ainda os que mencionaram apoiar as decisões dos(as) trabalhadores(as) do sexo.

4) Ausência de posição sobre o assunto (2 instituições).

Muito embora tivéssemos optado por dividir as opiniões nesses quatro grandes tipos de posição, na Tabela 1 podemos constatar a diversidade e a complexidade das respostas. Ressaltamos que, apesar de terem sido entrevistadas 32 pessoas, consideramos as respostas como equipe técnica, num total de 23 instituições, para o corpus da análise.

Tabela 1

Opinião dos Técnicos quanto à Moldura Política Vigente

\begin{tabular}{l|c}
\hline Posições Diferenciadas & Referências \\
\hline Paradigma opressão & 1 \\
$\quad$ Não à mudança & 1 \\
Não à mudança, mas abertos ao debate & 1 \\
$\quad$ Não à mudança e indiferença & 11 \\
Paradigma empoderamento & \\
$\quad$ Reconhecimento legal da atividade & 3 \\
Paradigma polimorfo & 2 \\
$\quad \begin{array}{l}\text { Abertos ao debate } \\
\text { Abertos ao debate e apoiam a opinião dos(as) trabalhadores(as) do sexo } \\
\text { Abertos ao debate, apoiam a opinião dos(as) trabalhadores(as) do sexo, } \\
\quad \text { mas não se posicionam }\end{array}$ & 1 \\
Abertos ao debate, mas não se posicionam & 1 \\
Sem opinião & 2 \\
$\quad$ Não se posicionam sobre o assunto & \\
\hline$\quad \mathrm{N}=23$ & \\
\hline
\end{tabular}

Fonte: Elaboração das autoras.

Destacamos, então, que grande parte desses profissionais defende uma mudança legal, mesmo que alguns ainda não apresentem uma ideia clara sobre em que moldes a mudança deveria ser processada.

No paradigma da opressão, os abolicionistas, na linha dos discursos feministas radicais, consideram que a prostituição é uma violação dos direitos humanos, cujo impacto "mexe de fato com a integridade, com a dignidade, com o autoconceito, com a autoestima [...]. Nesse sentido, 
entendemos que esse não poderá ser um trabalho equiparado a outros trabalhos [...]" (E5). Esses entrevistados consideram ainda que a prostituição é uma forma de violência que não pode ser, do ponto de vista deles, legalizada:

Repare que eu já acompanhei cerca de 8 mil mulheres [...] e há um padrão, chamemos assim, de fatores que convergem e que fazem parte de histórias de vida muito semelhantes, e o sofrimento não pode ser legalizado. Eu não posso dizer que esta mulher é feliz e que quer ser prostituta e optou, quando eu sei, a minha interpretação da realidade, e é feita com ela, nem sequer é feita só por mim, mas acho que o percurso da vida dela foi tudo, foi todo ele violento. Agora, dizem-me assim: mas há mulheres que se prostituem porque querem, há mulheres que optaram. Isso é um nicho de mercado, não é com esse nicho que eu trabalho, eu trabalho com outra multidão de mulheres, entende-me? (E12).

Nesse último testemunho, é perceptível certo distanciamento do posicionamento do feminismo radical ao considerar a possibilidade de opção das mulheres por essa atividade, mesmo não sendo expressivo. Salientamos que esses dois técnicos dirigem instituições que não fazem parte da RTS.

No paradigma do empoderamento, aqueles que se encontram a favor da regulamentação da atividade consideram que a prostituição exercida sob coação é uma forma de violência e não deve ser legitimada, distinguindo os que optam livremente por essa atividade: "[...] não consideramos que trabalho sexual é por si só uma forma de violência, mas somos contra qualquer forma de prostituição forçada [...]" (E4). No argumento apresentado a favor da legalização como combate ao tráfico, para identificar situações de exploração, E4 defende a fiscalização:

Nossa ideia era condenar de forma sistemática todas as situações de exploração e, para isso, é preciso haver fiscalização. Achamos que se devem regular os espaços, e não as pessoas; não devemos estar a regular as pessoas, mas abrir um bocadinho as portas para poder perceber o que é que funciona bem, se há algum tipo de exploração a acontecer, se há prostituição de menores, se há vítimas de tráfico, que nesse momento não acontece $[\ldots]$.

Esse entrevistado considera incorreto o argumento usado pelos feministas radicais segundo o qual a legalização aumenta o tráfico de seres humanos para fins sexuais: 
Porque desocultando [sic] o fenômeno vai permitir precisamente uma maior, uma melhor avaliação dessas situações. As redes criminais operam melhor na clandestinidade do que em fenômenos que estão regulados, por isso a nossa convicção é de que, se tiramos isso da marginalidade, vai aumentar a identificação de casos. Eu também acho que vai aumentar a identificação de casos, o que por si só deveria ser um argumento a favor da regulamentação [...] (E4).

Se esse conjunto de entrevistados menciona, na generalidade, a necessidade de regulamentação e a legalização da atividade, dois deles referem claramente que não concordam com a delimitação de zonas para a prática, com o registro dos(as) trabalhadores(as) do sexo e com exames periódicos obrigatórios, como acontece na maioria dos países que adotaram o regulamentarismo (E4, E14).

No paradigma polimorfo, encontram-se aqueles que são abertos ao debate, considerando importante equacionar as vantagens e desvantagens (E1, E13), adaptar o melhor modelo (E1, E2), tendo em vista a promoção da qualidade de vida das pessoas e seus direitos (E1, E9, E11, E13, E22, E23) e suas necessidades e opiniões (E2, E9, E11, E20, E22), tal como E9: "Agora, definir qual é a posição ideal ou qual era a situação ideal, isso só as próprias mulheres podem definir e a nós cabe apoiar essa decisão". Desses, três afirmam ainda claramente que apoiam e respeitam as decisões dos(as) trabalhadores(as) do sexo (E9, E11, E22), dois optam por não se posicionar politicamente, embora demonstrem preocupação com os direitos e necessidades da população (E20, E22). À semelhança dos entrevistados do paradigma da opressão e do empoderamento, não pactuam com o tráfico de seres humanos para fins sexuais:

Temos também a noção de que, muitas vezes associadas ao trabalho sexual, podem estar situações muito complicadas de exploração, mesmo de tráfico, e nós não somos coniventes com elas, portanto nós temos também, e cada vez mais, a [instituição] tem preocupações e está a tentar intervir na área do tráfico humano, e na área do tráfico humano sabemos que se inclui o tráfico para fins de exploração sexual (E20).

Os outros dois (E15, E18), que não tomam nenhuma posição, mostram também preocupação com a questão dos direitos.

Argumentos apresentados que fundamentam as posições. Procuramos conhecer a base de sustentação das posições tomadas, pelo que seguidamente apresentamos os argumentos utilizados pelos entrevistados. 
Argumentos do paradigma da opressão. Das três instituições a favor da manutenção do abolicionismo, apenas duas se consideram assumidamente a favor da prevalência do atual quadro legal e sustentam sua posição com base em argumentos como:

1) A atividade consiste numa forma de violência contra a integridade, a dignidade e os direitos humanos.

2) A legalização conduz ao aumento do tráfico, designadamente "porque, legalizando a prostituição, como na Holanda, o tráfico aumenta naturalmente, isto é, deixa de ser tráfico porque, se eu sou uma empresária do sexo, eu posso ir à Espanha contratar meninas para virem trabalhar para a minha empresa. Portanto, aqui a questão do tráfico fica diluída ou até apagada. Preocupa tanto a Comunidade Europeia... Nesse momento, deixa de existir porque passam a ser... a Holanda é o paradigma dessa situação, deixam de existir traficantes e passam a ser empresários, e que estão legalmente a desenvolver sua empresa no seu país, como acontece na Alemanha, como acontece na Holanda" (E12).

3) A legalização conduz ao aumento da prostituição: "Defendem-se questões da situação das que estão ilegais de poderem [pausa]... acho que isso pode ser perverso, de alguma forma, e pode ser contraproducente em algumas áreas. E, se calhar, pessoas que nunca lhe tinham passado pela cabeça e faziam parte dos seus princípios nunca recorreriam à prática da prostituição, se calhar, encontravam-se aí num país, que não o seu, portanto, em situação de imigração, se calhar, encontravam aí a única saída para conseguir sobreviver $[\ldots]^{\prime \prime}(\mathrm{E} 5)$.

4) O debate sobre a mudança do quadro legal é inapropriado em virtude de fatores como o contexto atual de crise ("Escolheram o sítio, o momento certo para dar a este governo a possibilidade de taxar a dignidade" - E12), da diversidade inerente à atividade ("Para mim, prostituição tem um conceito, striptease tem outro conceito, artistas pornôs têm outro conceito. Não posso meter isso tudo debaixo do mesmo chapéu, como é dito [...]" - E12) e da não consideração das opiniões dos(as) trabalhadores(as) do sexo: "Se conhecessem as pessoas, se compreendessem a história de vida das pessoas, se percebessem o sentir das pessoas que estão numa situação de prostituição, digo-lhe isso com toda a honestidade, nunca poderiam defender isso" (E12). 
Argumentos do paradigma do empoderamento. De acordo com esse grupo de entrevistados, a regulamentação da atividade seria benéfica por vários motivos:

1) Poderia ter como consequência a diminuição dos problemas associados ao trabalho sexual, havendo a possibilidade de as pessoas não se sentirem estigmatizadas, marginalizadas, mas sim reconhecidas (E4, E16, E21), não estarem sujeitas a situações de perda de dignidade e violência (E3, E4) e à clandestinidade (E4, E6), sendo que as imigrantes ilegais poderiam ter acesso à legalização (E6).

2) Poderia contribuir para uma melhoria nas condições de trabalho (E4, E14, E17), permitir um conjunto diversificado de alterações positivas: o acesso a prestações sociais (E4, E6, E8, E10, E14, E16, E17, E21); o combate à exploração de outras partes, como o preço dos anúncios no jornal e do arrendamento (E4); a possibilidade de identificar situações de exploração (E4); a facilidade para abandonar a atividade prostitutiva se assim o desejassem (E4) ou a possibilidade de organização do trabalho sexual, isto é, duas ou mais pessoas trabalhando em conjunto sem acusação de lenocínio (E4); mais controle higiênico-sanitário (E8).

Dentro dos prós, foi ainda referenciado por alguns entrevistados que o atual modelo não corresponde à realidade (E14, E16, E19). Destaca-se, então, que a diminuição dos problemas associados à prostituição, o acesso a direitos e o combate ao estigma e à discriminação foram os argumentos a favor mais evidenciados.

Argumentos do paradigma polimorfo. Esse grupo de entrevistados evidenciou a reflexão em torno das potencialidades da legalização do trabalho sexual, como a diminuição do estigma (E2, E22, E23) e da clandestinidade (E23); associados à possibilidade legal de opção de ingresso no trabalho sexual (E2) e à promoção do empoderamento dos(as) trabalhadores(as) do sexo (E2).

No entanto, os técnicos de algumas instituições, quer integrados no paradigma do empoderamento, quer no polimorfo, estão cientes dos perigos que uma mudança jurídica pode representar para os(as) trabalhadores(as) do sexo. Defendem, assim, uma legislação que combata o estigma associado ao trabalho sexual e aos(às) trabalhadores(as) do sexo e a discriminação (E2, E6, E8, E14, E21, E23), e mostram preocupação com a deturpação que uma proposta legislativa possa vir a sofrer 
quando apresentada ao legislador. Entre as consequências assinaladas, destacam-se a eventual adoção de modelos proibicionistas (E4); o controle sobre as pessoas, e não sobre a atividade (E8); a conjuntura socioeconômica atual e a supremacia da moral ante as evidências apresentadas pelos técnicos (E14), podendo pôr as pessoas numa situação de mais vulnerabilidade (E8, E14). Esses entrevistados reconhecem ainda o risco de não conhecerem a fundo as opiniões dos maiores interessados - os(as) próprios(as) trabalhadores(as) do sexo - e de ser uma opinião apenas dos técnicos (E1, E2, E8), bem como a noção da existência de diversas realidades dentro do trabalho sexual (E1, E2):

A atividade profissional não é igual para toda a gente e todas as pessoas; algumas pessoas na prostituição incluem umas práticas que outras não incluem, incluem sentimentos que outros não incluem, incluem determinado tipo de clientes que outros não incluem e, portanto, é muito difícil arranjar uma definição, arranjar um quadro legal que permita responder a toda a gente (E2).

Dessa forma, verificamos a existência de uma reflexão sobre os prós e os contras de uma mudança legislativa e constatamos que os entrevistados encontram mais argumentos a favor do que contra.

Perspectiva da Equipe Técnica sobre a Opinião dos(as) Trabalhadores(as) do Sexo. Uma vez que os técnicos, em sua maioria, têm uma posição definida quanto à moldura legislativa, com os respectivos argumentos, procuramos perceber que conhecimento eles têm sobre a opinião dos(as) trabalhadores(as) do sexo quanto a esse assunto. Entre as respostas, encontramos três grupos diferenciados:

1) Alguns técnicos desconhecem as opiniões dos(as) trabalhadores(as) do sexo porque nunca perguntaram (2), porque se encontram recolhendo-as (3) ou ainda porque esse assunto nunca surgiu nos atendimentos/contatos efetuados (3).

2) Há técnicos que revelam a ambivalência que caracteriza as posições dos(as) trabalhadores(as) do sexo quanto ao assunto, dado considerarem que esses(as) trabalhadores(as) gostariam de ver sua atividade regulamentada, mas não se assumiriam publicamente como tal (6), ou se encontram ponderando as vantagens e desvantagens de uma regulamentação (5).

3) Por último, sobressaiu a diversidade que os técnicos apontam relativamente às opiniões dos(as) trabalhadores(as) do sexo (11), o que 
reforça a necessidade de uma visão polimorfa dessa realidade, tal como postulam autores como Sanders, O'Neill e Pitcher (2011), Weitzer (2009), Piscitelli (2005), entre outros.

Não foi possível obter resposta de sete instituições a essa questão, das quais quatro responderam às questões por escrito.

Entre aqueles que apontam desconhecer as opiniões dos(as) trabalhadores(as) do sexo, cabe referir que dois nunca perguntaram a opinião desses(as) trabalhadores(as) sobre esse aspecto legal (E5, E17), sendo que um entrevistado se situa no paradigma da opressão, e outro no do empoderamento; os que se encontram na sondagem das opiniões procedem à aplicação de um inquérito (E1, E14, E22), estando dois no polimorfo e outro no empoderamento. Embora sem um conhecimento empírico estruturado, E1, E14, E18 e E22 afirmam que existe diversidade de opiniões e que aqueles que optam pelo regulamentarismo não assumem a profissão. E5 diz que não surge nos contatos e, quando acontece, é para ponderar vantagens e desvantagens na situação das imigrantes.

Os que já conhecem as opiniões dos(as) trabalhadores(as) do sexo afirmam que existe diversidade de opiniões, com pessoas ora a favor do abolicionismo, ora a favor da regulamentação. Das onze instituições que têm conhecimento sobre essa diversidade de opiniões entre os(as) trabalhadores(as) do sexo, cinco estão no polimorfo, cinco no empoderamento e uma não se posiciona sobre o assunto.

Nas leituras preliminares dos dados que efetuamos com o intuito de esboçar categorias de análise, não verificamos padrões de resposta ou correlações entre características individuais dos entrevistados (gênero, formação acadêmica, posição na instituição) ou a tipologia da instituição e as respostas obtidas. Assim, as diferenças encontradas parecem estar associadas ao desenvolvimento pessoal e à experiência subjetiva. Ressaltamos ainda que, embora muitos entrevistados tivessem salvaguardado que suas opiniões não refletem as da instituição, são esses técnicos, com seus quadros de referência, que atuam junto ao(às) trabalhadores(as) do sexo.

\section{CONSIDERAÇÕES FINAIS}

A história jurídico-legal sobre a prostituição demonstra as diversas tentativas fracassadas de erradicar a atividade ou de controlar as pes- 
soas que a desenvolvem, sob pretextos associados ao preconceito que mais contribuíram para a exclusão, a discriminação e a estigmatização das pessoas envolvidas na prostituição do que para a efetivação de seus direitos. É esperado então que um Estado laico aja em conformidade, tendo em vista quer as evidências que podem ser fundamentadas pela experiência dos técnicos que trabalham em proximidade com essa população, quer pela opinião dos(as) próprio(as) trabalhadores(as) do sexo. Nesse seguimento, o conceito de poder de Foucault (1990; 2008), como prática social difusa, plural, construído nas inter-relações discursivas e em sua articulação com as instituições, fornece uma base de significação e de objetivação aos micropoderes constituídos, que assumem um lugar de importância na legitimação do discurso da prostituição como trabalho sexual ou como crime.

Tal como nos paradigmas presentes nos estudos sobre a prostituição identificados por Weitzer (2009), encontramos, no decorrer de nosso estudo, quatro posições diferenciadas entre os profissionais das instituições que dirigem respostas a essa população: 1) assente na defesa do trabalho sexual como trabalho (mais expressivo); 2) prostituição como forma de violência contra os direitos humanos;3) neutralidade e reflexão; 4) sem posição sobre o assunto. Apesar do reconhecimento da necessidade de uma mudança legislativa, alguns desses profissionais não têm uma ideia clara sobre a forma como o trabalho sexual deve ser enquadrado. Curiosamente, os profissionais que se posicionam contra a prostituição como trabalho pertencem a instituições que desenvolvem sua intervenção com mulheres, pelo que questionamos em que medida essa posição poderá estar relacionada com discursos hegemônicos sobre a dominação masculina e a vitimação feminina, não conseguindo compreender de que forma interpretam a prostituição exercida por homens ou transgêneros. Em qualquer das situações, parece-nos que o debate deve ultrapassar as questões de gênero e de poder (Piscitelli, 2005), uma vez que os elementos que interagem em contexto de trabalho sexual se encontram integrados em teias mais complexas e sofisticadas de significados e significações para quem compra e para quem vende. No entanto, é também essencial que não se exclua do debate a questão do tráfico de seres humanos para fins sexuais, tal como também é apontado pelos entrevistados, independentemente de sua opinião sobre a prostituição.

Não obstante os esforços empreendidos pela Rede sobre Trabalho Sexual (RTS), a opinião dos(as) trabalhadores(as) do sexo permanece ainda bastante oculta, pelo que partilhamos duas questões que nos pare- 
cem centrais: de um lado, a questão de Agustín (2004) sobre saber se os(as) trabalhadores(as) do sexo partilham com os investigadores o que honestamente pensam ou partilham o que julgam ser o esperado; e, de outro, a interrogação de Weitzer (2010) ao avançar com a necessidade do paradigma polimorfo, questionando se as opiniões usualmente recolhidas contemplam a diversidade de tipos, contextos, condições estruturais e organizacionais do trabalho sexual. Em outras palavras, parece-nos que a proposta de mudança legislativa para o reconhecimento legal do trabalho sexual carece ainda de um conhecimento aprofundado e estruturado sobre as expectativas e opiniões dos envolvidos na prática. Acresce o risco de, mais uma vez, qualquer mudança empreendida ser sustentada na posição dos técnicos que impõem sua vontade, o que remete uma vez mais a questões relacionadas ao poder e à hegemonia das instituições.

Por fim, convém mencionar que, no caso da Nova Zelândia, paradigmático da descriminalização do trabalho sexual, Abel (2010) verificou que, embora a mudança em nível legislativo tenha permitido o acesso dos(as) trabalhadores(as) do sexo a um emprego legal, a direitos de saúde e de segurança ocupacional que lhes permitem negociar serviços sexuais seguros com os clientes e um maior controle sobre seu ambiente de trabalho, o peso do estigma continua presente, o que demonstra que possivelmente seja necessária uma mudança concernente a diversos níveis e com outras implicações, em que a educação para a sensibilização da sociedade civil poderá assumir papel fundamental.

Em suma, compreendemos que esses discursos polarizados surgem no seguimento da própria evolução da ciência, do debate feminista, das práticas sociais, da problematização do gênero e da conquista de direitos da mulher numa sociedade ainda dominada pela construção social do masculino. Entendemos também a objetivação do empoderamento de ambas as posições por meio do constructo foucaultiano de poder, $\mathrm{o}$ que sugere que o debate está longe de encontrar consenso. Contudo, uma vez que esses técnicos representam instituições que prestam serviços de apoio a trabalhadores(as) do sexo, não podemos deixar de questionar de que forma suas posições políticas influenciam o tipo de serviço prestado e as relações estabelecidas com seus clientes - os(as) trabalhadores(as) do sexo -, de modo que se sugere um aprofundamento do conhecimento nessa área.

(Recebido para publicação em junho de 2013)

(Reapresentado em agosto de 2014)

(Aprovado para publicação em junho de 2015) 


\section{NOTAS}

1. Disponível em <http://www.mtecbo.gov.br/cbosite/pages/home.jsf>. Acesso em 15 de abril de 2015.

2. O caso que se tornou midiático nos anos 1960 por envolver políticos do regime do Estado Novo com prostituição, incluindo prostituição infantil. Nenhum membro do governo foi condenado.

3. Disponível em <https://www.youtube.com/watch?v=HUU3Um1PwAY>. Acesso em 15 de abril de 2015.

4. APDES é uma das instituições que dirigem serviços a trabalhadores(as) do sexo. Assume um papel ativista na luta pelos direitos desses(as) trabalhadores(as) e é elemento da RTS.

5. A maioria das instituições presentes nesse mapeamento está inserida na RTS.

6. Uma das instituições por já não se encontrar com um projeto ativo na área do trabalho sexual; duas por não se identificarem com o propósito da RTS no âmbito em que foi elaborado esse mapeamento; e outras duas que não constam do mapeamento por motivos não explicitados. 


\section{REFERÊNCIAS BIBLIOGRÁFICAS}

ABEL, Gillian. (2010), Decriminalisation: A Harm Minimisation and Human Rights Approach to Regulating Sex Work. Tese (Doutorado em Filosofia), University of Otago, Dunedin.

AGÊNCIA PIAGET PARA O DESENVOLVIMENTO; REDE SOBRE TRABALHO SEXUAL; PEIXOTO, Vítor. (2012), Recomendações para a Redefinição do Enquadramento Jurídico do Trabalho Sexual em Portugal. Disponível em http: / / www.apdes. pt/assets/apdes/RTS/Recomendacaoes\%20RTS.pdf. Acesso em 15 de abril de 2015.

AGUSTíN, Laura María. (2004), “Alternate Ethics, or: Telling Lies to Researchers". Research for Sex Work, vols. 6-7.

AMADO, João; COSTA, António Pedro; CRUSOÉ, Nilma. (2013), “A Técnica da Análise de Conteúdo", in J. Amado (org.), Manual de Investigação Qualitativa em Educação. Coimbra, Imprensa da Universidade de Coimbra, pp. 301-351.

BARDIN, Laurence. (2004), Análise do Conteúdo. Lisboa, Edições 70.

BARRA DA COSTA, José Martins. (2003), “O Crime de Lenocínio. Do Direito à Prostituição", in J. Barra da Costa (org.), Sexo, Nexo e Crime. Teoria e Investigação da Deliquência Sexual. Lisboa, Edições Colibri, pp. 81-121.

; ALVES, Lurdes Barata. (2001), Prostituição 2001. O Masculino e o Feminino de Rua. Lisboa, Edições Colibri.

BARRY, Kathleen. (1986), “La Prostitution est un Crime”. Déviance et Société, vol. 10, no 3, pp. 299-303.

BASTOS, Susana Pereira. (1997), O Estado Novo e os seus Vadios. Contribuição para o Estudo das Identidades Marginais e da sua Repressão. Lisboa, Publicações Dom Quixote.

BOURDIEU, Pierre. (1999), A Dominação Masculina. Oeiras, Celta.

BROMBERG, Sarah. (1998), "Feminist Issues in Prostitution", in J. Elias et al. (orgs.), Prostitution. On Whores, Hustlers, and Johns. New York, Prometheus Books, pp. 294-321.

BURGESS, Ernest Watson; LOCKE, Harvey James. (1960), The Family. From Institution to Companionship. New York, American Book.

CARMO, Isabel do; FRÁGUAS, Fernanda. (2003), Puta de Prisão. Lisboa, Publicações Dom Quixote.

CHAPKIS, Wendy. (1997), Live Sex Acts: Women Performing Erotic Labor. New York, Routledge.

COUTINHO, Clara Pereira. (2011), Metodologia de Investigação em Ciências Sociais e Humanas: Teoria e Prática. Coimbra, Almedina.

D’AZEVEDO, Francisco Pereira. (1864), História da Prostituição e Polícia Sanitária no Porto. Porto, Casa de F. Gomes da Fonseca.

DELACOSTE, Frédérique; ALEXANDER, Priscilla. (1998), Sex Work. Writings by Women in the Sex Industry. 2a ed. California, Cleis Press.

DADOS - Revista de Ciências Sociais, Rio de Janeiro, vol. 59, no- 2, 2016 
DOEZEMA, Jo. (1998), “Forced to Choose. Beyond the Voluntary v. Forced Prostitution Dichotomy", in K. Kempadoo; J. Doezema (orgs.), Global Sex Workers. Rights, Resistance, and Redefinition. New York/London, Routledge, pp. 34-50.

FARLEY, Melissa. (2004), "Bad for the Body, Bad for the Heart": Prostitution Harms Women Even if Legalized or Decriminalized". Violence against Women, vol. 10, no 10, pp. 1087-1125.

FERREIRA, José Medeiros; BARREIRA, Cecília. (1993), “A Evolução Cultural e das Mentalidades", in J. Mattoso (org.), História de Portugal. Portugal em Transe (1974-1985). Lisboa, Círculo de Leitores, pp. 166-172.

FOUCAULT, Michel. (1990), História da Sexualidade 1. A Vontade de Saber. 10ª ed. Rio de Janeiro, Edições Graal.

. (2008), Microfísica do Poder. 26a ed. São Paulo, Rio de Janeiro, Graal.

GHIGLIONE, Rodolphe; MATALON, Benjamin. (2005), O Inquérito: Teoria e Prática. 4a ed. Oeiras, Celta.

GIDDENS, Anthony. (1993), Sociologia. Lisboa, Fundação Calouste Gulbenkian.

GOMES, Augusto Bugalho. (1913), História Completa da Prostituição. Lisboa, Auctor.

GUINOTE, Paulo; OLIVEIRA, Rosa Bela. (1989), “Prostituição, Boémia e Galanteria no Quotidiano da Cidade", in A. Reis (org.), Portugal Contemporâneo (1851-1910). Lisboa, Edições Alfa, pp. 339-382, vol. II.

KEMPADOO, Kamala. (2012), “Introduction: Abolitionism, Criminal Justice, and Transnational Feminism. Twenty-First-Century Perspectives on Human Trafficking", in K. Kempadoo; J. Sanghera; B. Pattanaik (orgs.), Trafficking and Prostitution Reconsidered. New Perspectives on Migration, Sex Work, and Human Rights. 2a ed. BoulderLondon, Paradigm, pp. vii-xlii.

LIBERATO, Isabel. (2002), Sexo, Ciência, Poder e Exclusão Social. A Tolerância da Prostituição em Portugal (1841-1926). Lisboa, Livros do Brasil.

LOPES, Ana. (2006), Trabalhadores do Sexo, Uni-Vos! Organização Laboral na Indústria do Sexo. Lisboa, Publicações Dom Quixote.

MATTOSO, José. (1993), “Mutações”, in J. Mattoso (org.), História de Portugal. A Monarquia Feudal (1096-1480). Lisboa, Círculo de Leitores, pp. 243-267, vol. 2.

MOSSMAN, Elaine. (2007), International Approaches to Decriminalising or Legalising Prostitution. Prepared for the Ministry of Justice. Wellington, New Zealand, Ministry of Justice.

NERI DE SOUZA, Francislê; COSTA, António Pedro; MOREIRA, António. (2011), “Análise de Dados Qualitativos Suportada pelo Software webQDA", Anais da VII Conferência Internacional de TIC na Educação: Perspectivas de Inovação (Challenges 2011). Braga, 12 e 13 de maio, pp. 49-56. Disponível em https:/ / www.webqda.com/ wp_site/wp-content/uploads/2012/06/artigoChallanges2011.pdf. Acesso em 15 de abril de 2015.

OLIVEIRA, Alexandra. (2004), As Vendedoras de Ilusões. Estudo sobre Prostituição, Alternee Striptease. Lisboa, Editorial Notícias.

. (2011), Andar na Vida. Prostituição de Rua e Reacção Social. Coimbra, Almedina. 
PACHECO, José. (2000), O Sexo por Cá. Lisboa, Livros Horizonte.

PAIS, José Machado. (1984), "Prefácio", in F. Santos Cruz (org.), Da Prostituição na Cidade de Lisboa. Lisboa, Publicações Dom Quixote.

. (2008), A Prostituição e a Lisboa Boémia do Século XIX a Inícios do Século XX. Lisboa, Ambar.

PISCITELLI, Adriana. (2005), "Apresentação: Gênero no Mercado do Sexo". Cadernos Pagu, no 25, pp. 7-23.

. (2012), “Feminismos e Prostituição no Brasil: Uma Leitura a partir da Antropologia Feminista". Cuadernos de Antropología Social, no 36, p. 11-31.

ROBERTS, Nickie. (1996), A Prostituição através dos Tempos na Sociedade Ocidental. Lisboa, Editorial Presença.

SANDERS, Teela; O'NEILL, Maggie; PITCHER, Jane. (2011), Prostitution. Sex Work, Policy \& Politics. London, Sage Publications.

SANTOS, Carlos Oliveira. (1982), "A Prostituição em Portugal nos Séculos XIX e XX". História, no 41, pp. 2-20.

SANTOS CRUZ, Francisco Ignacio. (1984) [1841], Da Prostituição na Cidade de Lisboa. Lisboa, Publicações Dom Quixote.

SCOTT, Joan Wallach. (1995), “Gênero: Uma Categoria Útil de Análise Histórica”. Educação \& Realidade, vol. 20, no 2, pp. 71-99.

SILVA, Susana. (2007), “Classificar e Silenciar: Vigilância e Controlo Institucionais sobre a Prostituição Feminina em Portugal”. Análise Social, vol. XLII, no 184, pp. 789-810.

STRAUSS, Anselm; CORBIN, Juliet. (2008), Pesquisa Qualitativa. Técnicas e Procedimentos para o Desenvolvimento de Teoria Fundamentada. 2a ed. Porto Alegre, Artmed.

SUBTIL, José. (1993), “Os Poderes do Centro”, in J. Mattoso (org.), História de Portugal. O Antigo Regime (1620-1807). Lisboa, Círculo de Leitores, pp. 157-271. vol. IV.

VALA, Jorge. (1986), “A Análise de Conteúdo”, in A. S. Silva; J. M. Pinto (orgs.), Metodologia das Ciências Sociais. Porto, Edições Afrontamento, pp. 101-128.

VIEIRA, Jorge. (1892), A Prostituição no Porto. Porto, Typographia de José da Silva Mendonça.

WEITZER, Ronald. (2009), "Sociology of Sex Work". Annual Review of Sociology, vol. 35, no 1, pp. 213-234.

. (2010), "Sex Work: Paradigms and Policies", in R. Weitzer (org.), Sex for Sale. Prostitution, Pornograhy, and the Sex Industry. 2a ed. New York, Routledge, pp. 1-43.

\section{Outras Fontes}

Código Penal Português. (1995), Disponível em http:/ / www.pgdlisboa.pt/leis/ lei_mostra_articulado.php?nid=109\&tabela=leis. Acesso em 15 de abril de 2015.

Decreto-Lei 35.042, de 20 de outubro de 1945. Organiza os serviços da Polícia Judiciária. Diário do Governo no 233 - I Série. Lisboa, Ministério da Justiça.

DADOS - Revista de Ciências Sociais, Rio de Janeiro, vol. 59, no 2, 2016 
Decreto-Lei 44.288, de 20 de abril de 1962. Aprova a Organização Tutelar de Menores. Diário do Governo no 89 - I Série. Lisboa, Ministério da Justiça.

Decreto-Lei 44.579, de 19 de setembro de 1962. Proíbe o exercício da prostituição a partir de 1o de janeiro de 1963. Diário do Governo no 216 - I Série. Lisboa, Ministérios do Interior e da Saúde e Assistência.

Decreto-Lei 400/82, de 23 de setembro de 1982. Aprova o Código Penal Português - descriminalização da prostituição e criminalização do lenocínio. Diário da República no 221 - I Série. Lisboa, Ministério da Justiça.

Lei 2.036, de 9 de agosto de 1949. Promulga as bases da luta contra as doenças contagiosas. Diário do Governo no 175 - I Série. Lisboa, Presidência da República. 


\section{RESUMO}

Prostituição: Que Modelo Jurídico-Político para Portugal?

A prostituição em Portugal conheceu diversos modelos jurídico-políticos, como a regulamentação, o proibicionismo e o abolicionismo, prevalecendo este último na atualidade. No discurso social e científico encontramos sobretudo duas posições: os defensores da prostituição como trabalho e os que a consideram uma violação dos direitos humanos. Este artigo apresenta a evolução histórico-legal dos modelos de intervenção na prostituição em Portugal, de forma a contextualizarmos e compreendermos a influência dos discursos. Em seguida, expõe as opiniões dos profissionais das instituições, que dirigem respostas a esta população, sobre a atual moldura jurídico-política, com a finalidade de analisar as diferentes perspectivas sobre o trabalho sexual. Baseando-se em pesquisa de natureza qualitativa que contemplou 23 entrevistas, conclui-se que embora não exista uma ideia clara sobre qual modelo adotar, a preocupação com o respeito pelos direitos humanos e o combate ao estigma estão patentes, independentemente do paradigma em questão.

Palavras-chave: prostituição; modelos jurídico-políticos; paradigmas do trabalho sexual; opinião dos técnicos

\section{ABSTRACT \\ Prostitution: Which Juridical-Political Model for Portugal?}

Different political-juridical models have framed prostitution in Portugal: regulation, prohibition and abolition, the latter of which is currently prevalent. There are two main standpoints in social and scientific discourse: those who defend prostitution as a valid form of labor and those who consider it a violation of human rights. This article presents the legal and historical evolution of models of interventions concerning prostitution in Portugal, so as to contextualize and understand the influence of discourses. Next, the article exposes the opinion of professionals within institutions that respond to the demands of this population, under the current political-juridical framework, with the objective of analyzing different perspectives on sexual labor. Based on qualitative research which tooks into account 23 interviews, it was concluded that although there is not a clear idea as to which model to adopt, the concern regarding respect for human rights and the combatting stigma is well-established, regardless of the paradigm in question.

Keywords: prostitutions; juridical-political models; paradigms of sexual labor; technical opinions 


\section{RÉSUMÉ}

Prostitution: Quel Modèle Juridico-Politique pour le Portugal?

La prostitution au Portugal a connu divers modèles juridico-politiques, tels que la réglementation, la prohibition et l'abolitionnisme, ce dernier étant celui qui prévaut actuellement. Dans le discours social et scientifique, deux positions dominantes se dessinent: la défense de la prostitution comme travail et l'idée selon laquelle elle constituerait une violation des droits humains. Cet article présentera l'évolution historico-légale des modèles d'intervention dans la prostitution au Portugal, de façon à contextualiser et à comprendre l'influence des différents discours. Nous exposerons ensuite les opinions sur le cadre juridico-politique émises par des professionnels d'institutions prenant en charge cette population spécifique, dans le but d'analyser les différentes perspectives sur le travail sexuel. Sur la base d'une étude qualitative comprenant 23 entretiens, nous avons conclu que même s'il n'existait pas d'idée claire sur le modèle à adopter, le respect des droits humains et la lutte contre la stigmatisation constituaient des préoccupations centrales, et ce indépendamment du paradigme en question.

Mots-clés: prostitution; modèles juridico-politiques; paradigmes du travail sexuel; opinions des professionnels

\section{RESUMEN}

Prostitución: ¿Qué Modelo Jurídico-Político para Portugal?

La prostitución en Portugal ha conocido a lo largo del tiempo diversos modelos jurídico-políticos: la reglamentación, el prohibicionismo y el abolicionismo, siendo este último todavía prevaleciente en la actualidad. En el discurso social y científico encontramos sobre todo dos posiciones: los defensores de la prostitución como trabajo y aquellos que la consideran una violación de los derechos humanos. Este artículo presenta la evolución histórico-letal de los modelos de intervención en la prostitución en Portugal, como forma de contextualizar y comprender la influencia de los discursos. Enseguida, expone las opiniones de los profesionales de las instituciones, que dirigen respuestas a esta población, sobre el actual marco jurídico-político, con la finalidad de analizar las diferentes perspectivas sobre el trabajo sexual. Basándose en una investigación cualitativa que contempló 23 entrevistas, la conclusión sugiere que aunque no exista una idea clara sobre que modelo adoptar, la preocupación con el respeto a los derechos humanos y el combate al estigma están patentes, independiente del paradigma en cuestión.

Palabras clave: prostitución; modelos jurídico-políticos; paradigmas del trabajo sexual; opinión de los técnicos 